\title{
US Employment Inequality in the Great Recession and the COVID-19 Pandemic
}

\author{
Steven M. Fazzari and Ella Needler ${ }^{*}$
}

\author{
Working Paper No. 154
}

March 31 ${ }^{\text {st }}, 2021$

\begin{abstract}
This article compares inequality in US employment across social groups in the Great Recession and the COVID-19 pandemic. We develop an inequality measure that captures both how much employment declines during a recession and the persistence of those declines. The results show a significant shift of job loss from men in the Great Recession to women in the COVID-19 lockdown. White workers fare better than other racial/ethnic groups in both recessions. Black and Hispanic women are hit especially hard in the COVID-19 pandemic. With our job loss measure, less educated workers had modestly worse outcomes in the Great Recession. However, during COVID-19, less educated workers suffer much more severe employment consequences than more educated groups. We discuss long-term effects of employment inequality and how these findings are relevant to debates about policy responses.
\end{abstract}

https://doi.org/10.36687/inetwp154

JEL codes: E24, J21

Key words: Employment, Unemployment, Inequality, Great Recession, COVID-19

\footnotetext{
${ }^{*}$ Washington University in St. Louis. Fazzari is a member of the INET Academic Council and a fellow of the Forum on Macroeconomics and Macroeconomic Policy (FMM). An earlier version of this paper was presented at the $24^{\text {th }}$ FMM conference, October 29, 2020
} 


\section{INTRODUCTION}

Understanding the impact of recessions on economic security, especially employment, motivates much of macroeconomics. Most analysis and commentary describes aggregate effects such as the peak-to-trough drop in employment, the rise in the unemployment rate, or the time it takes for employment to recover back to its pre-recession level. But as attention to rising economic inequality has risen in recent years, studies of recessions have increasingly considered connections between recessions and inequality. Most obviously, researchers have looked more deeply into how recessions have unequal effects on different segments of societies. In addition, some studies explore how inequality affects the conditions that lead to recessions and the course of recessions and recoveries. ${ }^{1}$

This article analyzes inequality in employment outcomes across social groups during recessions. We take a comparative perspective, studying results from two recent and severe US recessions: the "Great Recession" linked with the global financial crisis beginning in late 2007 and the "lockdown" recession caused by the COVID-19 pandemic. While comparing just two recessions in one country limits the generality of our findings, these are significant, recent downturns in a large economy caused by very different processes. Thus, comparing these two events presents an interesting case study to explore inequality in recessions.

We begin in section 2 with an overview of the two major recessions. We focus our analysis on employment dynamics and account for the fact that the severity of a recession depends both on the how much employment declines and the persistence of those declines. In section 3, we explain a simple, but to our knowledge original, measure that captures both of these dimensions: job-months lost, defined as the sum of monthly employment losses relative to the business cycle peak added over a given number of months since cycle peak. While the concept is simple, implementing it presents two challenges in our comparative context. First, we need to account for different employment trends across recessions and across demographic groups we study. Second, we need to deal with the very different dynamics of the Great Recession (relatively slow decline in employment followed by a very slow recovery) compared with the COVID-19 lockdown (dramatically sharp fall in employment and quick partial bounce back).

Section 4 presents our main results based on data from the US Current Population Survey (CPS). We compare the share of job-months lost for a variety of demographic groups to the share of the groups' total employment at the economy's peak before the two recessions. Our results show:

\footnotetext{
${ }^{1}$ Studies that analyze the unequal effects of recessions include Kreuger et al. (2017) and Amroin et al. (2018). Examples of research that consider how inequality affects the macroeconomic dynamics of recession include Barba and Pivetti (2009), Cynamon and Fazzari $(2015,2016)$, and Auerbach, et al. (2020). Heterodox growth models in the Kaleckian tradition have, for decades, emphasized the impact of the functional distribution of income between wages and profits, an economic characteristic closely related to inequality. This research is summarized and interpreted in several recent book length treatments including Hein (2013), Lavoie (2014), and Blecker and Setterfield (2019).
} 
- A significant shift of the burden of job losses from men in the Great Recession to women in the COVID-19 lockdown.

- White workers fare better than Asian, Black, and Hispanic employees in both recessions. Black and Hispanic women are hit especially hard in the COVID-19 pandemic.

- Young workers suffer disproportionate, and similar, job losses in both recessions. Middle age workers have been affected less severely in the COVID-19 crisis than in the Great Recession. Older workers have done much worse in COVID-19 compared with the Great Recession.

- Job-months lost in the Great Recession were somewhat skewed toward workers with lower education (a good proxy for income), but, when appropriately accounting for trends, the inequality across education groups in the Great Recession was less pronounced than often described. However, less educated workers suffer dramatically more employment loss due to COVID-19 than more educated groups.

While our main results emphasize how recessions magnify pre-existing inequalities in the short term, section 5 considers how the inequalities caused by recessions affect longer term trends of inequality and how inequality matters for long-term growth. Section 6 concludes with a brief summary and discussion of policy implications of our findings.

\section{TWO HISTORIC RECESSIONS}

As early as the 1990s, mainstream macroeconomists declared victory in the war against deep recessions. Developed economies had entered a period described as the "Great Moderation" (Stock and Watson, 2002). Conventional economic wisdom came to believe that monetary policy is the primary tool for macroeconomic stabilization and, when implemented wisely, it should keep recessions modest. Indeed, after the deep and disruptive recession of the early 1980s, the US experienced a quarter century with only two mild recessions.

The global financial crisis and subsequent Great Recession shattered this benign view. For a few scary months in late 2008 and early 2009, job losses mimicked the collapse of the early 1930s. Unemployment soared. Despite aggressive monetary policy, including a rapid drop of short-term interest rates to zero, the recession continued and governments summoned fiscal tools to attempt a rescue. The worst of the economic bleeding stopped by mid-2009, but recovery was slow. It continually disappointed conventional forecasts that projected a return of the US economy to its pre-crisis trend. Some mainstream economists, most prominently Lawrence Summers (2014, 2018), began to sound more heterodox. Summers resurrected the concept of "secular stagnation" due to insufficient aggregate demand growth, while politically motivated conservatives blamed excessive regulation and anticipated tax increases due to President Obama's policies. But all agreed the 2008-09 collapse and subsequent recovery showed historic weakness in the US economy.

Although the recovery beginning in 2009 was weak, it was persistent. Indeed, it would have surely lasted longer had the public health crisis created by COVID-19 not hit the economy like a 
sledgehammer in the spring of 2020. After 113 months of positive job growth, US payroll employment declined by more than 22 million jobs (14.5 percent) in March and April. Although the Great Recession employment decline was historically severe it was not nearly as rapid (25 months from the January 2008 peak to the February 2010 trough) and the total job loss was 6.3 percent, less than half of the peak-to-trough loss caused by the COVID-19 lockdown. But the US job market surprised many of us with a remarkably quick bounce back in the summer of 2020 . The economy added more than 12 million jobs from May through October (4.8 million in June alone). But as virus infections rose in the fall, as predicted by epidemiologists, the jobs recovery stalled. As of December 2020, US payroll employment remained 6.5\% below its February peak, about the same as the job loss percentage at the trough of the Great Recession labor market.

These two recessions were both severe, but with different dynamics. They provide a useful laboratory for exploring how recessions beget inequalities and how these inequalities differ across two major downturns with markedly different sources and characteristics. It is useful to note, however, that both recessions were the result of demand-side effects that dominated any problems on the supply side. The dominance of demand in the Great Recession is widely accepted. This conclusion is less obvious for the COVID-19 crisis, however. The lockdown obviously discouraged spending on activities that expose people to infection (cruises, air travel, restaurants, in-person entertainment and sporting events, ...). But it is also obvious that lockdowns had direct supply impact, such as the shutdown of auto manufacturing for several weeks in the spring of 2020. Supply also became a binding constraint on production of items for which demand surged due to the crisis (personal protection equipment, bicycles, gym supplies, home office furniture, cleaning products ...).

To get a broad sense of whether supply-side or demand-side effects dominated the recession, we look at price data. Figures $1 \mathrm{a}$ and $1 \mathrm{~b}$ show price level trends for the personal consumption expenditure price indicies (the Federal Reserve's preferred inflation measure) leading up to and through the Great Recession and the COVID-19 crisis. ${ }^{2}$ In both crises, inflation declined. For the headline measure that includes all items prices fell significantly in the Great Recession and the COVID-19 crisis. The "core" measure that excludes volatile food and energy prices shows effectively zero inflation in the Great Recession and a substantial decline in the COVID-19 crisis. In addition, interest rates plummeted in both recessions, inconsistent with what would be expected if supply shocks were the dominant engine of recession. While one can identify some possible supply effects in the Great Recession and large certain supply effects in the COVID-19 crisis, the evidence shows demand contractions dominated, a finding relevant for both analytical and policy purposes.

\footnotetext{
${ }^{2}$ Price data from the Consumer Price Index have similar patterns.
} 


\section{Figure 1a - Personal Consumption Prices, Great Recession}

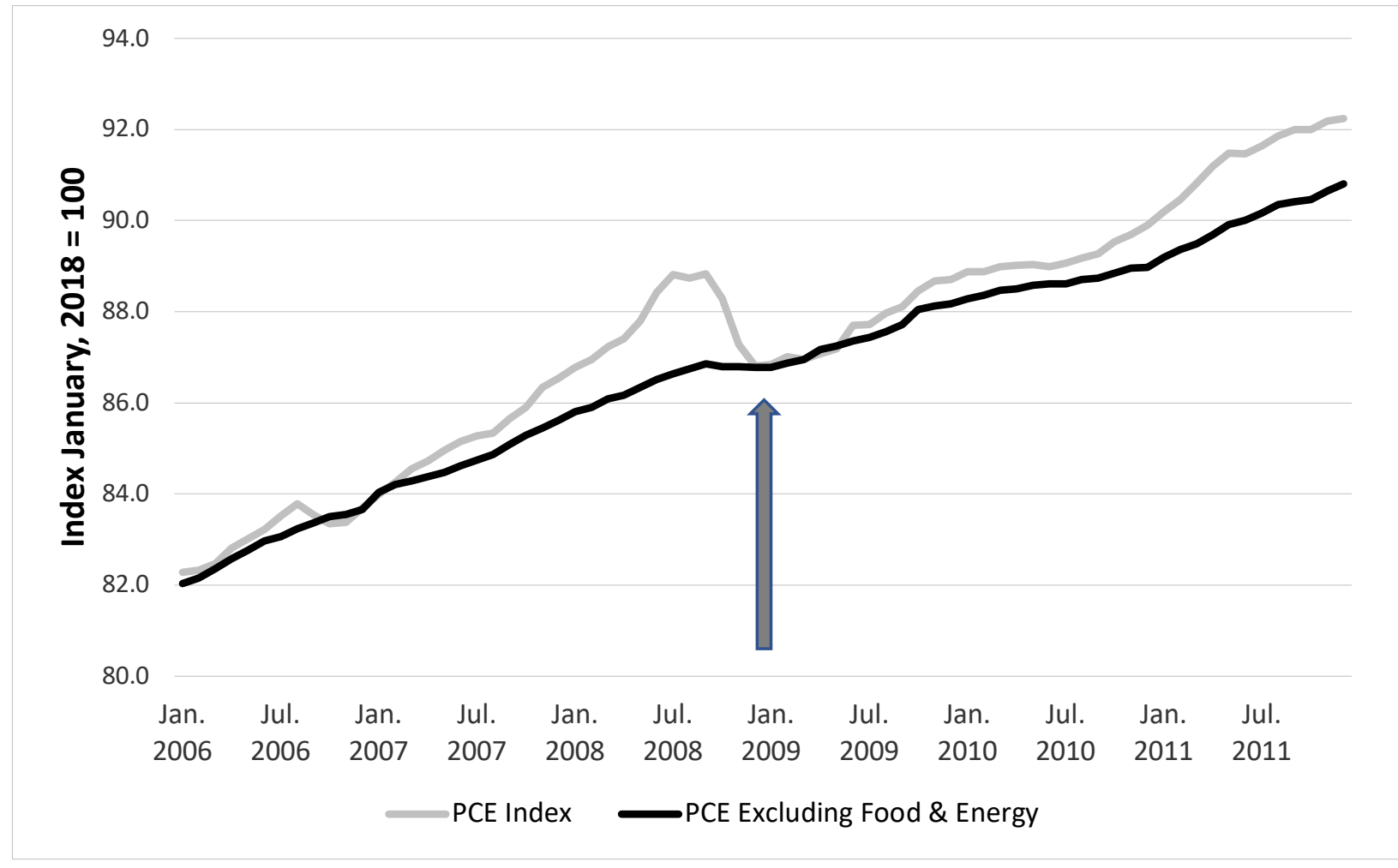

Figure 1b - Personal Consumption Prices, COVID-19 Recession

106.0

105.0

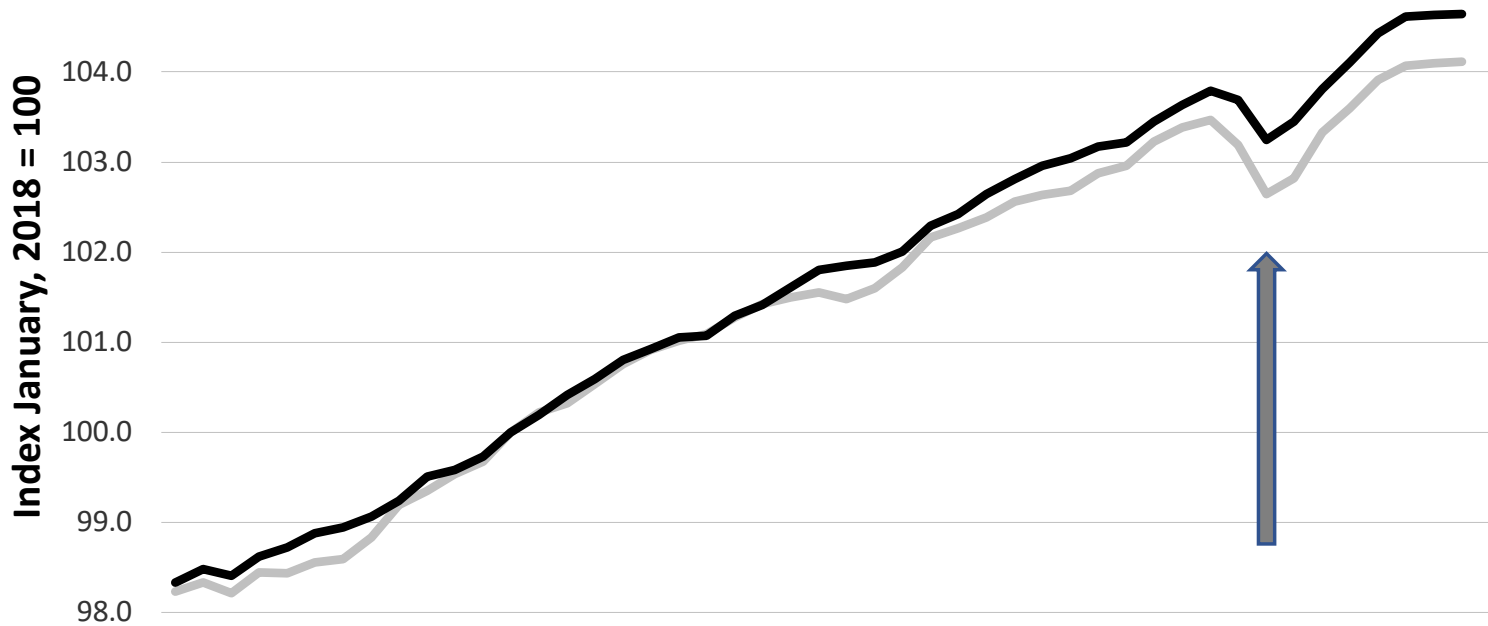

97.0

Jan. 2017 Jul. 2017 Jan. 2018 Jul. 2018 Jan. $2019 \quad$ Jul. $2019 \quad$ Jan. $2020 \quad$ Jul. 2020

PCE Index —PCE Excluding Food \& Energy 


\section{MEASURING LABOR MARKET INEQUALITY}

To measure inequality in the job market we analyze employment for gender, race, age and education level with data from the US CPS conducted monthly by the Bureau of Labor Statistics. This is the same survey used to determine the monthly headline unemployment rate. ${ }^{3}$ We focus on employment rather than unemployment because individuals who stop working during a recession will not be counted as unemployed if they stop actively searching for a new job. This kind of job loss could be particularly important in the COVID-19 recession when parents (disproportionately mothers) were forced to leave work to care for children who could no longer attend in-person child care or school. Also, workers in hard hit industries such as restaurants may have seen little reason to actively seek new jobs when the industry almost completely shut down. ${ }^{4}$

As discussed earlier, our analysis needs to account for both the severity and persistence of job losses. The different dynamics of the Great Recession and the COVID-19 recession confirm the importance of considering both dimensions of recession employment. The remarkably fast and deep job losses in the early months of the COVID-19 recession dwarfed the job losses in any similar period of the Great Recession. And the trough of employment relative to the peak was much lower in COVID-19. That said, the initial job recovery was much faster in the summer of 2020 than the slow and painful job growth following the Great Recession. Figure 2 provides an example of this issue. It shows the CPS data for female employment from several years before the Great Recession through the most recent data on the COVID-19 crisis available at this writing (December 2020). Both recessions are obvious, but there is ambiguity about which is worse: sharp and very deep (COVID-19) versus more shallow but more persistent (Great Recession).

The figure also shows that pre-recession trends in employment figures are relevant to assessing the severity of job losses. In the example of female employment in Figure 2, it is clear that normal pre-recession job figures had a strong upward trend. Recession effects designed to explore inequality should be measured relevant to these trends that we find differ across splits of the data. ${ }^{5}$

\footnotetext{
${ }^{3}$ Total employment numbers, such as the ones we mention in section 2 , are usually taken from the payroll employment reports which are less volatile than the CPS household survey. However, payroll employment data are not stratified by demographic groups. The CPS data count employment for all individuals age 16 and above, except for the education splits which count individuals aged 25 and up.

${ }^{4}$ While the CPS data source is widely used to assess labor market outcomes, Cai and Baker (2021) present evidence showing unemployment for Black and Hispanic workers (especially young Black males) could be distorted downward in the CPS due to the absence of survey responses. This possibility suggests that the results we present here may understate the true extent of job loss inequality for under-represented minority populations.

${ }^{5}$ We use a simple linear trend estimated for 36 months prior to the peak employment that precedes each recession. The trend is calibrated so that actual employment equals trend employment at the pre-recession peak. Of course, there are good reasons to question whether simple linear trends capture "normal" employment dynamics that could reasonably have been expected to continue in the absence of a recession. For example, rising average age of the
} 
Figure 2 - Female Employment in the Great Recession and COVID-19 Crisis

80000

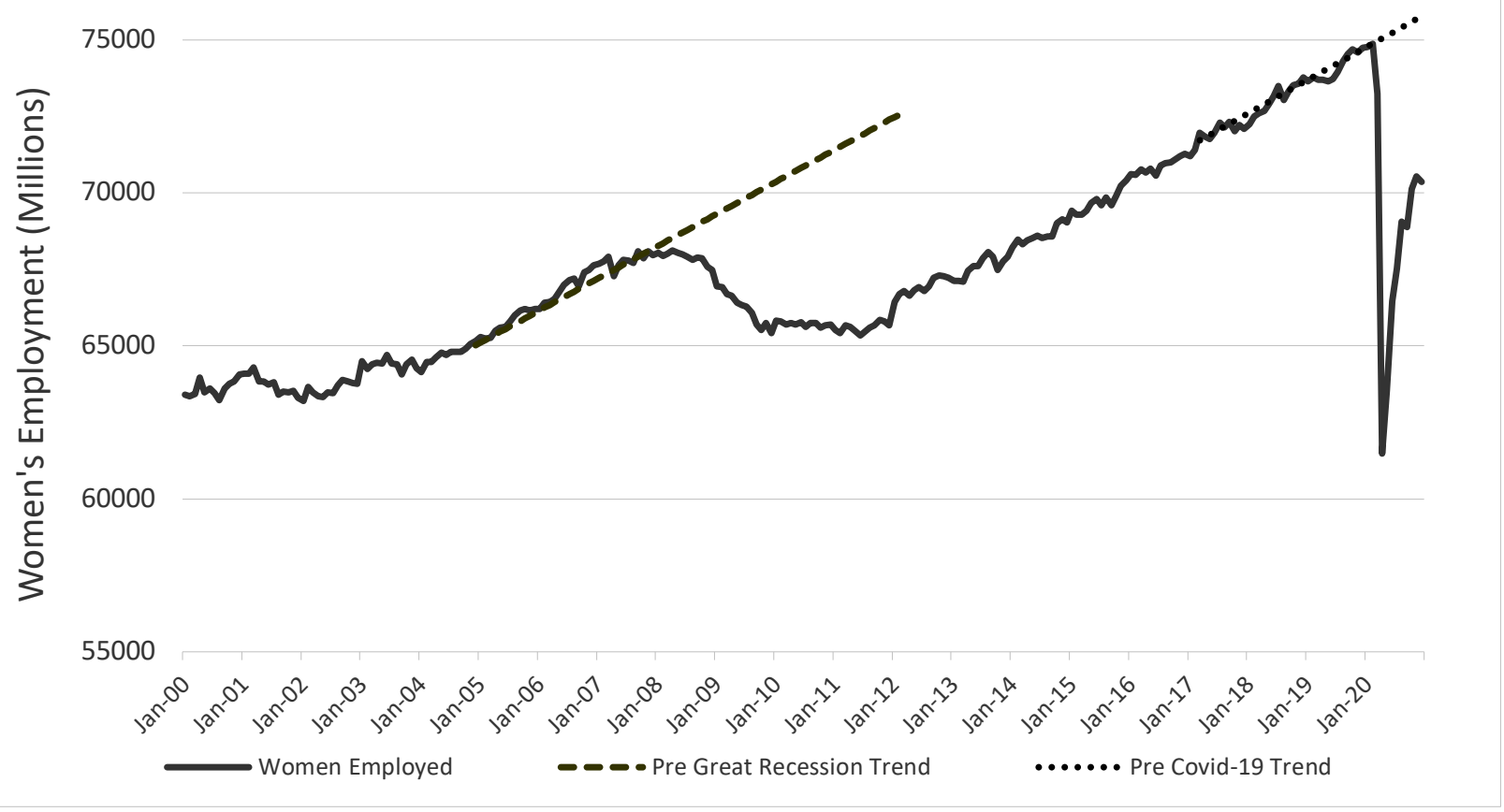

We propose a simple measure of employment disruption that combines both the depth of job losses and their persistence: job-months lost. This statistic simply adds the difference between actual employment and the pre-recession trend for a given number of months following the prerecession peak. Effectively, job-months lost is the area between actual employment and the benchmark trend on a graph such as figure 2, up to a specified horizon.

To implement this calculation, we need to choose an ending horizon for each recession. The choice is simple for the COVID-19 crisis. As of this writing, we have 10 recession months of data since the February 2020 peak (that is, March through December) and we use all of these months. The choice is less clear for the Great Recession. We could use just 10 months, but since the Great Recession played much out more slowly, this choice would greatly understate both the depth and persistence of job losses in that crisis. ${ }^{6}$ For our primary statistics, we use a 36-month

labor force likely slows trend growth. Such effects, however, play out slowly over time. For our short-run analysis, nonlinearities in the trend likely play a minor role.

${ }^{6}$ Job-months lost relative to trend in the first 10 months of the Great Recession were just $13 \%$ of the losses first 10 months of the COVID-19 recession. But as one extends the horizon, these figures change dramatically because the deepest job losses in the Great recession were 12 to 25 months after the beginning of the downturn and there is virtually no recovery relative to trend. We made some simple projections of the recovery profile for COVID-19 anticipating fast growth when the vaccine becomes widespread in the summer of 2021. With these projections, we estimate ultimate job-months lost for a 36-month horizon in the COVID-19 crisis will be $25 \%$ less than the 36month job-months lost figure for the Great Recession (all calculations are relative to pre-recession trends). 
horizon for the Great Recession, but we consider the robustness of results with shorter and longer horizons as discussed in the next section. Another timing issue arises from defining the start of the Great Recession employment crisis for different demographic groups. The CPS total employment series peaks in November of 2007 before declining into the recession (consistent with the conventional definition of the start of the recession in December 2007). We use this start date for the Great Recession for the statistics presented in the tables to follow. However, for some demographic groups, employment before the Great Recession peaks a few months earlier or later than the aggregate peak. Our main results are not much affected by adjusting the Great Recession peaks for different start dates. For the COVID-19 crisis, the peak is clearly in February 2020 for all groups.

\section{COMPARING EMPLOYMENT INEQUALITY ACROSS RECESSIONS}

Table 1 presents the first set of our primary empirical results to illustrate how gender inequality shifted between the Great Recession and the COVID-19 crisis. At the peak of employment before the recession, men held $53.6 \%$ of total CPS jobs, but during the 36 months following the peak, cumulative job-months lost for men accounted for $63.8 \%$ of total job-months lost during this period. Our key statistic is the ratio of these two shares, the job-months lost share to the share of jobs held before the recession began. If this ratio is one, cumulative job losses over the recession horizon would be equal to the share of the group's pre-recession jobs implying an equal impact. However, for men in the Great Recession our ratio statistic is 1.19 (equal to 63.8\% / 53.6\%), indicating that men did substantially worse during the recession than their share of employment would suggest. In contrast the ratio statistic for women of 0.78 implies women did better than implied by their share of the jobs alone (and even though women did lose jobs during the recession). ${ }^{7}$

Table 1 - Gender Inequality

\begin{tabular}{|l|c|c|}
\hline Great Recession (36-month horizon) & Men & Women \\
\hline Pre-recession peak share of jobs & $53.6 \%$ & $46.4 \%$ \\
\hline Share of job-months lost & $63.8 \%$ & $36.2 \%$ \\
\hline Ratio of loss share to initial share & 1.19 & 0.78 \\
\hline \hline COVID-19 Crisis (10-month horizon) & & \\
\hline Pre-recession peak share of jobs & $52.8 \%$ & $47.2 \%$ \\
\hline Share of job-months lost & $48.5 \%$ & $51.5 \%$ \\
\hline Ratio of loss share to initial share & 0.92 & 1.09 \\
\hline
\end{tabular}

\footnotetext{
${ }^{7}$ Although we consider 10 months too short a horizon to fully assess the Great Recession, these figures do not change meaningfully even if the horizon for the Great Recession calculations is shortened to 10 months. These findings show our conclusions are robust with respect to alternative assumptions.
} 
Men taking a greater relative hit to employment in the Great Recession than women is not surprising since the crisis hit manufacturing and residential construction employment particularly hard, both sectors in which men constitute a much larger share of employment than women. But these inequalities reverse in the first 10 months of the COVID-19 crisis. Women recently suffered a disproportionate share of job-months lost while men did a little better than their prerecession employment share would suggest. Two reasons jump out for this significant shift in impact. First, COVID-19 hit service jobs particularly hard in industries such as restaurants, travel, and (perhaps surprisingly) health care, all sectors in which women hold a larger share of the jobs. Second, women have been disproportionately affected by additional childcare duties as COVID-19 shut down schools and childcare centers. Collins et al. (2021) find much larger effects of the pandemic on labor force participation for mothers than for fathers in states where schools shifted primarily to remote instruction (Alon et al., 2020, make related comparisons; also see Covington and Kent, 2020). These job losses arise both from layoffs and from women leaving their jobs and not moving immediately back into employment, as one would expect would happen if childcare responsibilities inhibited womens' labor force participation.

Table 2 presents our results for several race / ethnic groups. It is clear that recessions magnify inequality by race and ethnicity. The job-months lost share for white workers is significantly lower in both recessions we study than their share of jobs at the beginning of the recession. Correspondingly, Black, Hispanic, and Asian groups are hit relatively more severely in both recessions. However, so far in the COVID-19 crisis employment inequality for Hispanic and Asian groups appears somewhat smaller than it did in the Great Recession.

Table 2 - Race/Ethnicity Inequality

\begin{tabular}{|l|c|c|c|c|}
\hline Great Recession (36-month horizon) & White & Black & Hispanic & Asian \\
\hline Pre-recession peak share of jobs & $73.4 \%$ & $9.8 \%$ & $12.6 \%$ & $4.3 \%$ \\
\hline Share of job-months lost & $61.3 \%$ & $12.3 \%$ & $19.5 \%$ & $6.8 \%$ \\
\hline Ratio of loss share to initial share & 0.84 & 1.26 & 1.55 & 1.60 \\
\hline \hline COVID-19 Crisis (10-month horizon) & & & & \\
\hline Pre-recession peak share of jobs & $67.8 \%$ & $10.9 \%$ & $15.7 \%$ & $5.7 \%$ \\
\hline Share of job-months lost & $58.8 \%$ & $14.0 \%$ & $20.5 \%$ & $6.7 \%$ \\
\hline Ratio of loss share to initial share & 0.87 & 1.29 & 1.31 & 1.19 \\
\hline
\end{tabular}

The figures in table 2 that combine men and women hide some important differences across the two recessions. Table 3 shows the ratio statistics of the job-months lost share to the pre-recession 
job share stratified by both race/ethnicity and gender. ${ }^{8}$ Gender differences within race-ethnicity groups are stunning. For all race/ethnicity groups, men do relatively worse in the Great Recession while women do worse in the COVID-19 crisis, broadly supporting the results in table 1. But the data in table 3 show how race and ethnicity magnify the gender differences. The three non-white groups of men were hammered in the Great Recession. Inequalities among men are evident in the COVID-19 recession as well, but the differences are smaller than in the Great Recession. The results are very different for women. White women experienced much smaller employment effects in the Great Recession than their job share would predict. So far in the COVID-19 recession, white women are slightly disadvantaged (ratio statistic of 1.05), but Black and Hispanic women's employment has been decimated with ratio statistics of 1.42 and $1.60 .{ }^{9}$ Asian women had severe job-months lost in the COVID-19 months, but they also suffered inequality in the Great Recession. According to our measure of recession severity in the job market, the service-sector shutdown of COVID-19 compromised the employment of all female groups relative to the male groups, but the effects are magnified among under-represented minorities.

Table 3 - Ratio of Job-Month Loss Share to Pre-Recession Job Share by Gender and Race/Ethnicity

\begin{tabular}{|l|c|c|c|c|}
\hline & $\begin{array}{c}\text { White } \\
\text { Men }\end{array}$ & $\begin{array}{c}\text { Black } \\
\text { Men }\end{array}$ & $\begin{array}{c}\text { Hispanic } \\
\text { Men }\end{array}$ & $\begin{array}{c}\text { Asian } \\
\text { Men }\end{array}$ \\
\hline Great Recession (36-month horizon) & 0.99 & 1.69 & 1.67 & 1.53 \\
\hline COVID-19 Crisis (10-month horizon) & 0.71 & 1.08 & 1.08 & 1.28 \\
\hline \hline & $\begin{array}{c}\text { White } \\
\text { Women }\end{array}$ & $\begin{array}{c}\text { Black } \\
\text { Women }\end{array}$ & $\begin{array}{c}\text { Hispanic } \\
\text { Women }\end{array}$ & $\begin{array}{c}\text { Asian } \\
\text { Women }\end{array}$ \\
\hline Great Recession (36-month horizon) & 0.70 & 0.83 & 1.29 & 1.24 \\
\hline COVID-19 Crisis (10-month horizon) & 1.04 & 1.42 & 1.60 & 1.36 \\
\hline
\end{tabular}

Table 4 presents data stratified by age group. Even though the youngest workers are a relatively small share of the labor force, they are hit disproportionately hard in both recessions. There may be some back-to-school phenomena operating in this group. But note that these statistics measure jobs lost. A decision by a high-school student to go to community college rather than into the

\footnotetext{
${ }^{8}$ Note that the data used for table 3 do not aggregate to the figures in table 2 for two reason. First, seasonal adjustments are not available for some series used in table 3. For consistency, we used non-seasonally adjusted data for all calculations summarized in table 3 . Second, the pre-recession trends in table 3 are estimated separately for each gender / race-ethnicity group while trends used in the table 2 calculations are estimated for all members of the race-ethnicity groups, both men and women.

${ }^{9}$ Covington and Kent (2020) provide related intersectional data on the female unemployment rate from November 2020. For all women, the rate was $6.1 \%$, for Black women $8.7 \%$, and Hispanic women $7.9 \%$.
} 
work force after graduation would not generate a job loss. These statistics reflect people who were working and stopped working. Middle-age workers had neutral results in the Great Recession, with job-months lost very similar to their pre-recession employment share. In the COVID-19 crisis, middle-age workers experienced a much smaller share of job-months lost than their population share. We expect some advantage for middle-age workers in the ability to work remotely, but the size of their advantage during COVID-19 is somewhat surprising. The share of job-months lost for workers 55 years of age and older in the Great Recession was dramatically lower than their pre-recession employment share (the 0.54 ratio statistic is the second lowest among all we present in this article). But in the COVID-19 crisis the older worker group is hit roughly as hard as their employment share, much worse than for middle-age workers. We propose three possible explanations for this finding. First, the significant cross-recession difference may be partially due to occupation. Older workers were likely under-represented in the more physically demanding manufacturing and construction sectors that were hit the hardest in the Great Recession. Second, Bureau of Labor Statistics data cited by Gould (2020) imply older workers are less likely to be able to work remotely. Third, and perhaps most important, relatively greater health risks likely caused older workers to leave jobs requiring in-person work in disproportionate numbers during the COVID-19 crisis. Bui et al. (2020) and the references they provide related data and describe various channels through which recessions in general, and COVID-19 in particular, affect older workers.

Table 4 - Age Inequality

\begin{tabular}{|l|c|c|c|c|c|}
\hline Great Recession (36-month horizon) & $\mathbf{1 6 - 2 4}$ & $\mathbf{2 5 - 3 4}$ & $\mathbf{3 5 - 4 4}$ & $\mathbf{4 5 - 5 4}$ & $\mathbf{5 5 +}$ \\
\hline Pre-recession peak share of jobs & $13.6 \%$ & $21.6 \%$ & $23.3 \%$ & $23.7 \%$ & $17.9 \%$ \\
\hline Share of job-months lost & $24.0 \%$ & $20.3 \%$ & $22.7 \%$ & $23.3 \%$ & $9.7 \%$ \\
\hline Ratio of loss share to initial share & 1.77 & 0.94 & 0.98 & 0.98 & 0.54 \\
\hline \hline COVID-19 Crisis (10-month horizon) & & & & & \\
\hline Pre-recession peak share of jobs & $12.4 \%$ & $22.7 \%$ & $21.0 \%$ & $20.1 \%$ & $23.8 \%$ \\
\hline Share of job-months lost & $20.7 \%$ & $24.9 \%$ & $15.4 \%$ & $14.3 \%$ & $24.7 \%$ \\
\hline Ratio of loss share to initial share & 1.68 & 1.09 & 0.73 & 0.71 & 1.04 \\
\hline
\end{tabular}

The final dimension of inequality we consider is education. This split is highly correlated with measures of socio-economic status such as income and wealth. The statistics in table 5 show there is clear inequality across the education groups in the Great Recession, with job-months lost generally greater relative to population for the lower two education groups compared to 
individuals who have at least some college education. ${ }^{10}$ These results may seem somewhat less unequal than expected, however. A major reason that job-months lost in our analysis are higher for college educated workers, and lower for workers with less than a high school diploma, is that we account for pre-recession trends. If one ignores trends, job declines for people with college degrees in the Great Recession are minimal. But this group was growing strongly before the downturn and losses relative to the local trend, rather than the peak level of employment at the beginning of the recession, provide a more accurate benchmark for analyzing the effects of recession. In contrast, the number of jobs held by workers without a high school diploma was trending down prior to the Great Recession. Ignoring this trend would cause one to overstate the extent of job-months lost for this group.

Table 5 - Educational Inequality

\begin{tabular}{|l|c|c|c|c|}
\hline Great Recession (36-month horizon) & $\begin{array}{c}\text { Less than } \\
\text { High School }\end{array}$ & $\begin{array}{c}\text { High } \\
\text { School }\end{array}$ & $\begin{array}{c}\text { Some } \\
\text { College }\end{array}$ & $\begin{array}{c}\text { College } \\
\text { Degree }\end{array}$ \\
\hline Pre-recession peak share of jobs & $8.9 \%$ & $29.2 \%$ & $27.7 \%$ & $34.3 \%$ \\
\hline Share of job-months lost & $8.8 \%$ & $36.2 \%$ & $25.1 \%$ & $29.9 \%$ \\
\hline Ratio of loss share to initial share & 0.98 & 1.24 & 0.91 & 0.87 \\
\hline \hline COVID-19 Crisis (10-month horizon) & & & & \\
\hline Pre-recession peak share of jobs & $6.6 \%$ & $25.2 \%$ & $26.0 \%$ & $42.3 \%$ \\
\hline Share of job-months lost & $12.6 \%$ & $38.1 \%$ & $27.6 \%$ & $21.7 \%$ \\
\hline Ratio of loss share to initial share & 1.92 & 1.51 & 1.06 & 0.51 \\
\hline
\end{tabular}

In the COVID-19 crisis, even after accounting for the trends toward more education, the inequalities across education groups are massive. The COVID-19 ratio statistic for the less than high school group (1.92) is the highest of any in our study while the ratio statistic for collegeeducation workers $(0.51)$ is the lowest. The education sample split identified only modest inequality in the Great Recession but it shows massive inequality in the COVID-19 crisis. Considering the strong correlation of education with income, wealth, poverty, food security and other socio-economic status indicators, this finding is especially concerning.

The source of this remarkable magnification of inequality in recent months almost certainly arises from the unique characteristics of the COVID-19 crisis. Less educated workers are more concentrated in sectors such as restaurants, hospitality, and retail that have been decimated by the public health crisis. These jobs also cannot be done remotely. In contrast, college-educated

\footnotetext{
${ }^{10}$ Educational differences for the Great Recession are somewhat more sensitive to our timing assumptions than other data presented in this article. In particular, a shorter horizon for the Great Recession calculations increases the advantage for the higher education groups.
} 
workers are much more likely to be able to work from home (see Bartik et al., 2020). When more educated and relatively affluent people stop going out to restaurants and stop shopping to protect their health it is the less educated, lower income people who lose their jobs.

\section{LONG-TERM EMPLOYMENT AND INEQUALITY EFFECTS}

The statistics presented in the previous section focus on the unequal employment effects of recessions. They demonstrate how these inequalities have been more severe in the COVID-19 crisis compared to the Great Recession, especially across education groups. These unequal effects on employment, for the duration of the recession and its immediate aftermath, raise the assessment of the social costs of recessions for anyone concerned about inequality. Furthermore, causation running from recession inequalities to long-term social consequences increases the importance of these problems.

As Catherine Rampell writes in the Washington Post, "[p]ast research has found that the longer a worker is unemployed, the more difficulty that person will have ultimately returning to work whether because of stigma, skill deterioration, severed relationships with past employers or other factors." 11 These effects may seem have seemed to be less of a concern in the COVID-19 crisis as US employment appeared to bounce back very quickly in May and June of 2020. But the recovery slowed, especially as the pandemic reasserted itself in November and December of 2020. Payroll employment actually fell again in December and preliminary numbers for January 2021 look very weak. The percentage decline in total jobs at the end of 2020 relative to the February peak was still greater than the worst peak-to-trough employment gap in the Great Recession and labor force participation remains depressed. Permanent job losses and detachment from the labor force during the COVID19 crisis will likely have widespread effects on employment prospects for years to come and these effects will be greater for disadvantaged groups. ${ }^{12}$

Focusing on the gender inequalities specifically, Alon et al. (2020) discuss how flexibility in female labor force participation created a kind of insurance for households against recession income losses in the past as women enter the labor force when their male partners lose their jobs in those sectors usually hit hardest in recessions, such as manufacturing and construction (also see Lundberg, 1985). But this buffering effect was compromised in the COVID-19 crisis because sectors in which women were most likely to seek employment were hit much harder than in other recessions. And women had to bear a disproportionate share of the additional childcare burden caused by the elimination of in-person schooling.

\footnotetext{
${ }^{11}$ February 5, 2021, https:/www.washingtonpost.com/opinions/2021/02/05/january-jobs-report-COVID-relief-need. Also see Irons (2009).

${ }^{12}$ Cheng et al. (2020) propose that most workers rehired in the initial bounce back phase from the COVID-19 crisis likely went back to their previous employers. But they also argue that the longer a separation lasts, the harder it will be for unemployed workers to be rehired.
} 
For all workers, unemployment and time out of the labor force compromises future employment and wage prospects. Perhaps the unusual circumstances of the COVID-19 crisis will mitigate the stigma of unemployment for job searchers, but longer-term negative consequences are likely. And, because of the great inequality in COVID-19 job losses, any unemployment stigma will be highly unequal. Perhaps these concerns are more severe for older workers. As table 4 shows, the relative job-months lost statistics for workers older than 55 are much worse in the COVID-19 recession than in the Great Recession. Will these people ever get back to work? Higher labor force participation among older people who are living longer is a possible response to the macro challenges of declining population growth. Therefore, COVID-19 possibly poses a greater "hysteresis" threat to long-term economic growth than the typical recession. Furthermore, many Americans have inadequate savings to maintain their consumption in retirement. Working longer beyond normal retirement age is one obvious response to this situation. But, again, COVID-19 raises the barriers to this strategy, compromising both living standards for older cohorts and long-term consumption growth in an aging population.

More broadly, rising inequality is widely recognized to reduce aggregate demand. The primary reason is simple: high income groups recycle less of their income back into consumption than those with moderate or low incomes. This structural feature is central to the post-Keynesian research linking income distribution to macroeconomic performance (see footnote 1). The inequality by education group documented in the previous section is especially relevant for understanding longer-term demand consequences of the COVID-19 crisis. Our job-months lost statistics show the employment impact of the current recession are enormously greater on lower education groups, much more severe than in the Great Recession. As education is highly correlated with income, this inequality implies weaker consumption in the crisis and in its aftermath as these unequal employment effects drag on with the potential to reduce long-run economic growth led by demand. ${ }^{13}$

\section{RECESSIONS ARE BAD; INEQUALITY MAKES THEM WORSE}

Unemployment creates economic hardship and psychological stress for individuals and families. At the macroeconomic level, unemployment spills over through the multiplier to weaken incomes even for those who manage to keep their jobs in recessions, and unemployment wastes valuable productive resources. As bad as these outcomes are in the aggregate, inequalities in the way recessions destroy jobs magnify the personal and social costs.

This article explores inequality in recessions by comparing stratified outcomes across a variety of social groups. We use a measure of the employment impact of recessions that accounts for both the depth and the persistence of job losses: job-months lost. This measure is well suited to document employment inequality. We also gain insight from a comparative lens by contrasting

\footnotetext{
${ }^{13}$ Fazzari et al. (2020) present a model some empirical evidence to show how slower long-run demand growth reduces the long-run path of supply and potential output.
} 
unequal employment effects of the 2008-09 Great Recession with the COVID-19 economic crisis of 2020 .

Relative to their share in population the severity of employment effects by gender reversed between the two crises we studied. Men were hit harder in the Great Recession and women experienced disproportionate losses in the COVID-19 crisis. Black, Hispanic, and Asian workers experience greater losses in both recessions. Inequalities across racial-ethnic groups as a whole are not much different between the Great Recession and the COVID-19 recession, but the employment inequality for Black and Hispanic women is dramatically higher in the COVID-19 crisis. The youngest workers suffer larger employment effects than their population share would imply in both recessions. While employment losses for workers over 55 were surprisingly small in the Great Recession, older workers suffered much greater job losses in the current crisis. The education inequalities are perhaps the most striking in our study, particularly as they differ across the two recessions. In the Great Recession, our job-months lost statistics show only a small disadvantage for the lower education groups. But the disadvantage of lower education is dramatic in the COVID-19 crisis. Education, of course, is highly correlated with income, wealth, and other measures of socio-economic status. ${ }^{14}$

As of this writing, the COVID-19 crisis is ongoing, and our results will need to be updated to get a full sense of the employment effects. However, given the massive job losses early in the recession and the substantial bounce back in late spring and early summer, a large share of the employment consequences of the crisis have been realized by the end of 2020 and we do not expect the relative inequality results to change significantly through the remainder of this cycle.

These findings emphasize the importance of effective policy to contain and, in the future, prevent recessions. The need for effective intervention to offset the macroeconomic effects of recessions is reasonably well accepted among policy makers, especially in the aftermath of the Great Recession when the fiscal response was, according to many economists, inadequate. The additional evidence on inequality and recessions, especially the COVID-19 recession, increases the urgency for effective policy. Recognizing how recessions hurt the welfare of the most vulnerable members of society increases the significance of the social costs beyond what aggregate measures imply on their own. Furthermore, the unequal effects of recessions, and the persistence of these unequal effects after the downturn ends, slows or even reverses progress toward the worthy social goal of creating more equitable societies.

\footnotetext{
${ }^{14}$ Jerome Powell, Chair of the US Federal Reserve, was quoted in the New York Times on February 10, 2021 stating that employment dropped 4 percent for high-wage workers but "a staggering 17 percent" for workers in the bottom quartile of the income distribution. (https://www.nytimes.com/2021/02/10/business/economy/jerome-powell-fedemployment.html). Data from the Opportunity Insights website show 21 percent employment losses between January 2020 and January 2021 for workers with wages below \$27,000 annually, while employment rose 3 percent for workers earning more than $\$ 60,000$ per year (https://tracktherecovery.org).
} 
Understanding the unequal effects of recessions also focuses attention on the importance of targeting recession relief effectively at a more micro level. Obviously, unemployment benefits are particularly important as unemployed workers bear the brunt of recession costs. The U.S. unemployment insurance system is uneven across states and, in many states, woefully inadequate to provide even the most basic support to workers who lose their jobs, especially if the unemployment effects are persistent. Large federal supplements to unemployment in the COVID-19 pandemic have helped considerably. But political fights around the extension and renewal of these benefits create unnecessary uncertainty for those families most severely affected by the crisis. A more generous system with a larger role for the federal government is needed. ${ }^{15}$ Federal efforts are also needed to improve efficient access to unemployment assistance; stories of huge backlogs and bottlenecks around unemployment insurance have been rampant in the COVID-19 crisis. The inequalities induced by macroeconomic fluctuations also reveal the great need for institutional reforms not specifically associated with recessions. A prime example is support for childcare and family leave. It is clear that gender inequalities in employment are to a large extent the result of the need to care for children who could no longer attend school or day care in person during the pandemic (see Collins 2020 and Collins et al., 2021).

Shifting our focus to the macroeconomic implications of inequality, the most obvious point is that magnification of inequality during and after the recession will likely reduce consumption, lower aggregate demand, and slow the growth of the economy. This effect would be confined largely to the "short run" of textbook macroeconomics, but heterodox theory and evidence identifies reasons that low demand can constrain output, employment, and living standards "beyond the short run," as recognized by the recent prominence of the "secular stagnation" concept. ${ }^{16}$ These considerations show how the inequality effects of the recession increase the need for effective macroeconomic policy.

The connection between recessions, inequality and macroeconomic policy has another, somewhat more subtle, implication. Our results demonstrate how individuals and families in lower socio-economic circumstances suffer more severe effects from the recession. The goal of social equity, therefore, implies they should receive disproportionate relief from policies designed to stimulate the aggregate economy. This point relates to the debate in the U.S. about the size and distribution of "stimulus checks" sent to American households. These payments are a fixed amount per person up to a certain income level, after which the payments phase out. Some economists oppose this kind of demand stimulus because much of it will be saved rather than consumed, leading to less impact on demand. The criticism has some relevance, especially in the midst of a pandemic when people cannot or choose not to spend on many discretionary activities to protect their health. But lump-sum payments of a constant amount across individuals have a much bigger proportional impact on lower income households. A disproportionate share

\footnotetext{
15 The U.S. federal government is also much better able to accommodate the fiscal needs of recession relief since federal budgets, unlike most states, can run significant deficits during recessions.

${ }^{16}$ For a brief and recent perspective see Stansbury and Summers (2019). Fazzari (2020) adds context to this point.
} 
of these households will be affected directly by the pandemic and be in critical need of this assistance. For lower-income households that may have dodged income losses during the recession, the lump-sum payment will still be a welcome, and significant, financial boost. If they do not spend the funds, they can pay down debt or build some reserve for future financial shocks. These payments, at least during the pandemic, are a step toward the important social goal of greater economic equality. 


\section{REFERENCES}

Alon, T., Doepke, M., Olmstead-Rumsey, J, and Tertilt, M. (2020): This time it's different: the role of women's employment in a pandemic recession, NBER working paper 27660, August.

Amromin, G, De Nardi, M. and Schulze, K (2018): Inequality and recessions, Chicago Fed Letter, number 392.

Auerbach, A.J., Gorodnichenko, Y. and Murphy, D. (2020): Inequality, fiscal policy and COVID19 restrictions in a demand-determined economy, NBER working paper number 27366.

Barba, A. and Pivetti, M. (2009). Rising household debt: its causes and macroeconomic implications: a long period analysis, Cambridge Journal of Economics, 33(1), 113-137.

Blecker, R. and Setterfield, M. (2019): Heterdox Macroeconomics: Models of Demand, Distribution and Growth, Cheltenham, UK and Northampton, MA: Edward Elgar.

Bartik, A.W., Cullen, Z.B., Glaeser, E.L., Luca, M., and Stanton, C.T. (2020): What jobs are being done at home during the COVID-19 crisis? Evidence from firm-level surveys, NBER working paper 27422, June.

Bui, T.T.M., Button, P., Picciotti, E.G. (2020): Early evidence on the impact of COVID-19 and the recession on older workers, NBER working paper 27448, June.

Cai, Y. and Baker, D (2021): Missing Voters and Missing Unemployed Black Workers, Institute for New Economic Thinking, March 3, https://www.ineteconomics.org/perspectives/blog/missing-voters-and-missing-unemployedblack-workers

Cheng, W., Carlin, P., Carroll, J, Gupta, S., Rojas, F.L., Montenovo, L., Nguyen, T.D., Schmutte, I.M., Scrivner, O. Kosali, S.I., Wing, C. and Weinberg, B. (2020): Back to business and (re)employing workers? Labor market activity during state COVID-19 reopenings, NBER working paper 27419, June.

Collins, C. (2020): Who to blame and how to solve it: mothers' perceptions of work-family conflict across western policy regimes, Journal of Marriage and Family, 82(3), 849-874.

Collins, C., Ruppanner, L., Landivar, L.C., and Scarborough, W. (2021): The gendered consequences of a weak infrastructure of care: school reopening plans and arents' employment during the COVID-19 Pandemic, Gender \& Society, forthcoming.

Covington, M. and Kent, A (2020): The "She-Cession" persists, especially for women of color, On the Economy Blog, Federal Reserve Bank of St. Louis, December 24, https://www.stlouisfed.org/on-the-economy/2020/december/she-cession-persists-women-ofcolor. 
Cynamon, B.Z. and Fazzari, S.M. (2015b): Rising inequality and stagnation in the US economy, European Journal of Economics and Economic Policy, 12(2), 170-82.

Cynamon, B.Z. and S.M. Fazzari (2016): Inequality, the Great Recession and slow recovery, Cambridge Journal of Economics, 40(2) 373-399.

Fazzari, S.M. (2020): Was Keynesian economics ever dead? If so, has it been resurrected? Review of Keynesian Economics, 8(1), 46-60.

Fazzari, S.M., Ferri, P., and Variato, A. (2020): Demand-led growth and accommodating supply, Cambridge Journal of Economics, 44(3) 583-605.

Gould, E. (2020): Older workers can't work from home and are at a higher risk for COVID-19, Economic Policy Institute Working Economics Blog, March 31, https://www .epi.org/blog/older-workers-cant-work-from-home-and-at-high-risk-for-covid$19 /$.

Hein, E. (2014): Distribution and Growth after Keynes, Cheltenham, UK and Northampton, MA: Edward Elgar.

Irons, J (2009): Economic scarring: the long-term impacts of the recession, Economic Policy Institute Briefing Paper \#243, September.

Krueger, D. Mittman, K, and Perri, F. (2017): On the distribution of welfare losses of large recessions, (with), in B. Honoré, A. Pakes, M. Piazzesi and L. Samuelson (eds) Advances in Economics and Econometrics: Volume 2, Cambridge, UK: Cambridge University Press, 143-184

Lavoie, M. (2014): Post Keynesian Economics: New Foundations, Cheltenham, UK and Northampton, MA: Edward Elgar.

Lundberg, S. (1985): The added worker effect, Journal of Labor Economics, 3(1), 11-37.

Summers, L.H (2014): U.S. economic prospects: secular stagnation, hysteresis, and the zero lower bound, Business Economics, 49(2), 65-73.

Summers, L.H. (2018): The threat of secular stagnation has not gone away, blog post, http://larrysummers.com/2018/05/06/the-threat-of-secular-stagnation-has-not-gone-away.

Stansbury, A. and Summers, L.H. (2019): Whither central banking? Project Syndicate, 23 August.

Stock, J and Watson, M (2002): Has the business cycle changed and why? NBER Macroeconomics Annual, 17, 159-218. 